\title{
Anterior cervical dynamic ABC plating with single level corpectomy and fusion in forty-two patients
}

\author{
NE Epstein*,1,2,3,4 \\ ${ }^{1}$ The Albert Einstein College of Medicine, Bronx, NY, USA; ${ }^{2}$ Department of Neurosurgery, The North Shore-Long \\ Island Jewish Health System, Manhasset, NY, 11030, USA; ${ }^{3}$ New Hyde Park, NY 11040, USA; \\ ${ }^{4}$ Winthrop University Hospital, Mineola, NY 11501, USA
}

Study Design: Forty-two consecutive patients undergoing dynamic ABC plated one-level ACF utilizing iliac crest autograft (38 patients) and fibula allografts (four patients) were evaluated. The unique ABC slotted plate design allows for up to $10 \mathrm{~mm}$ of cephalad and 10 $\mathrm{mm}$ of caudad plate migration.

Objectives: To evaluate the incidence and etiology of complications in forty-two patients undergoing anterior cervical dynamic ABC plating (Aesculap, Tuttlingen, Germany), during one level anterior corpectomy with fusion (ACF).

Setting: New York, USA.

Methods: Serial dynamic X-ray and 2 Dimensional CAT Scan (2D-CT) studies, obtained 3, 6 , and up to 12 months postoperatively, in 42 patients documented the presence of fusion or complications including plate or graft extrusion or pseudarthrosis.

Results: Four $(9.5 \%)$ of 42 patients developed postoperative plate or graft-related complications during the average follow up interval of 34 months. One patient, with a plate/graft extrusion, required a second two level ACF with posterior wiring and fusion (PWF). Two patients with pseudarthroses and one patient with a delayed iliac crest strut fracture required secondary PWF.

Conclusions: Effective arthrodesis and a low incidence of complications following one level $\mathrm{ACF}$ performed utilizing dynamic $\mathrm{ABC}$ plates were attributed to reduced stress shielding and greater graft compression afforded by the unique plate design. Applying dynamic $\mathrm{ABC}$ plates for one level ACF was biomechanically advantageous with low morbidity.

Spinal Cord (2003) 41, 153 -158. doi:10.1038/sj.sc.3101418

Keywords: dynamic; plating; anterior; cervical; corpectomy; fusion

\section{Introduction}

Plate-related complications following anterior cervical procedures for contiguous disc disease combined with spondylosis or ossification of the posterior longitudinal ligament demonstrating retrovertebral extension, include graft or plate extrusion, fractures, and pseudarthrosis. ${ }^{1-12}$ To address complications the dynamic $\mathrm{ABC}$ plates were developed allowing for up to $10 \mathrm{~mm}$ of cephalad and $10 \mathrm{~mm}$ of caudad migration, reducing stress shielding and allowing for graft settling. One level anterior cervical corpectomy with fusion (ACF) performed with autologous iliac crest (38 patients) or fibula allografts (4 patients) were performed utilizing 42 dynamic $\mathrm{ABC}$ plates. Fusion or graft and plate-related failures and pseudarthrosis were

*Correspondence: NE Epstein, Long Island Neurosurgical Assoc., P.C., 410 Lakeville Rd. Suite 204, New Hyde Pk, NY 11042, USA documented on serial postoperative dynamic X-ray and 2D-CT studies obtained 3, 6, and up to 12 months postoperatively.

\section{Materials and methods}

Dynamic plates

Dynamic $\mathrm{ABC}$ plates have a unique slotted design allowing up to $10 \mathrm{~mm}$ of cephalad and $10 \mathrm{~mm}$ of caudad plate migration. The screw heads lock into the slots but allow the plate to slide over the screw heads. Variable angle screws toggle up to $34^{\circ}$, facilitating screw application.

Dynamic plates were applied in 42 patients with two level disc disease, spondylosis, and/or ossification of the posterior longitudinal ligament with significant retrovertebral extension who required single level corpect- 
omy with fusion (Figure 1) (Table 1). Patients averaged 44 years of age including 23 males and 19 females. The Nurick Myelopathy Scale was employed to grade preoperative and postoperative neurological status. This Scale includes Grades 0-V: Grade 0: radiculopathy, Grade I: mild myelopathy, Grade II: mildmoderate myelopathy, Grade III: moderate myelopathy, Grade IV: moderate - severe myelopathy, Grade V: severe myelopathy. ${ }^{4-8}$ Preoperatively, all patients' exhibited moderate myeloradiculopathy (average Nurick Grade 2.9), while postoperatively they all improved to a level of mild residual radiculopathy/mild myelopathy (average Nurick Grade of 0.4).

Single level anterior corpectomy with fusion (ACF) in 42 patients employed iliac crest autografts in 38 , three having fresh frozen fibula allografts implanted for morbid obesity and one for technical reasons; deep wound, shallow vertebral width (Table 2, Case 3). Nineteen patients weighted over $200 \mathrm{lbs}$, the average weight being $193 \mathrm{lbs}$ (range 140-320). Iliac crest grafts averaged $36 \mathrm{~mm}$ in length; the plate was typically $46 \mathrm{~mm}$ long. Surgery averaged $3 \mathrm{~h}$ in duration for 22 patients. Patients were discharged an average of 3.5 days postoperatively, and were followed an average of 34 months.

Single level ACF included partial resection and partial perforation of the respective cephalad and caudad vertebral end plates with removal of the intervening discs and vertebral body; ie C5-C7. Nonreversed iliac crest autografts were applied in all patients except four who received fresh frozen fibula struts.

Fusion and plate-related complications were documented on static X-ray, dynamic X-rays, and CT studies (2-D in particular). Serial examinations were obtained from 2-6 months postoperatively, or until fusion or plate-related failures were confirmed at up to 12 months. ${ }^{5,13}$ Static X-ray and 2D-CT fusion criteria

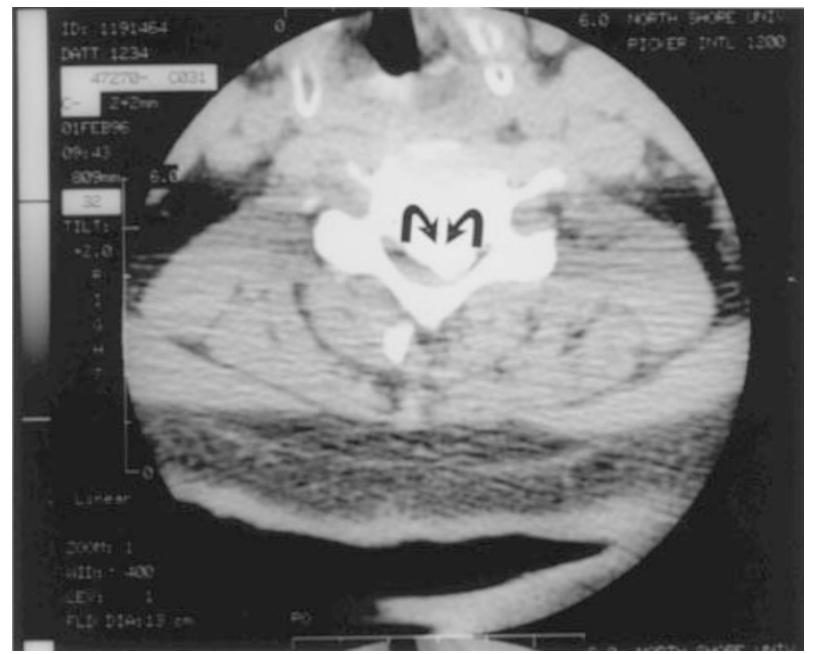

Figure 1 Transaxial non-contrast CT examination obtained at the mid-C6 vertebral body level where OPLL nearly fills the left side of the spinal canal (double arrows) included the lack of bony lucency, and the presence of bony trabeculation, while dynamic films confirmed lack of active motion $(<1 \mathrm{~mm})$ between contiguous spinous processes.

Of note, 5 of 15 similar patients undergoing fixedplated single level ACF developed plate and/or graftrelated failures; one plate extrusion (6 weeks postoperatively), two pseudarthroses (6 months postoperatively), and two delayed iliac crest strut fractures (1 and 2 years postoperatively). Fixed-plated patients were followed an average of 44 months.

\section{Results}

Dynamic plate series

Fusion was confirmed on both dynamic radiographs and 2D-CT studies in 38 of 42 patients an average of 3.7 months postoperatively (Table 1) (Figures 2 and 3 ).

Table 1 Dynamic plated patients undergoing single level $\mathrm{ACF}$

\begin{tabular}{|c|c|}
\hline Category & $\begin{array}{l}\text { Dynamic Plated } \\
1 \text { level ACF } \\
\text { ( } 42 \text { patients) }\end{array}$ \\
\hline $\begin{array}{l}\text { Average age } \\
\quad \text { (Range) }\end{array}$ & $\begin{array}{l}44 \\
(23-67)\end{array}$ \\
\hline \multicolumn{2}{|l|}{ Sex } \\
\hline Males & 23 \\
\hline Females & 19 \\
\hline $\begin{array}{l}\text { Average preoperative Nurick grade } \\
\text { (Range) }\end{array}$ & $\begin{array}{l}2.9 \\
(2-4)\end{array}$ \\
\hline $\begin{array}{l}\text { Average postoperative Nurick grade } \\
\text { (Range) }\end{array}$ & $\begin{array}{l}0.4 \\
(0-3)\end{array}$ \\
\hline \multicolumn{2}{|l|}{ Surgery } \\
\hline $\mathrm{ACF} \mathrm{C} 2-\mathrm{C} 4$ & 1 \\
\hline $\mathrm{ACF} \mathrm{C3-C5}$ & 3 \\
\hline $\mathrm{ACF} \mathrm{C} 4-\mathrm{C} 6$ & 7 \\
\hline $\mathrm{ACF} \mathrm{C} 5-\mathrm{C} 7$ & 31 \\
\hline $\begin{array}{l}\text { Average plate length } \\
\text { (Range) }\end{array}$ & $\begin{array}{l}46 \mathrm{~mm} \\
(37-55 \mathrm{~mm})\end{array}$ \\
\hline $\begin{array}{l}\text { Average operative time } \\
\text { (Range) }\end{array}$ & $\begin{array}{l}3 \mathrm{~h} \\
(2.5-5.0 \mathrm{~h})\end{array}$ \\
\hline Type of plate used in 42 patients & Dynamic ABC plates \\
\hline $\begin{array}{l}\text { Average time to fusion } \\
\text { (Range) }\end{array}$ & $\begin{array}{l}3.7 \text { months } \\
(2.5-7 \text { months })\end{array}$ \\
\hline Average follow-up interval & $\begin{array}{l}34 \text { months } \\
(24-41 \text { months })\end{array}$ \\
\hline \multicolumn{2}{|l|}{ Reoperations: } \\
\hline Plate or graft extrusion & 1 \\
\hline Pseudarthrosis & 2 \\
\hline Delayed iliac crest fracture & 1 \\
\hline
\end{tabular}


Table 1 Four dynamic plate-related failures following 1 level ACF

\begin{tabular}{|c|c|c|c|c|}
\hline Case number & Case 1 & Case 2 & Case 3 & Case 4 \\
\hline Age & 56 & 42 & 51 & 39 \\
\hline Sex & M & $\mathrm{M}$ & M & $\mathrm{M}$ \\
\hline Smoker & 1 pack/day & 2 pack/day & No & 2 pack/day \\
\hline Height & $5^{\prime} 6^{\prime \prime}$ & $5^{\prime} 3^{\prime \prime}$ & $6^{\prime} 4^{\prime \prime}$ & $5^{\prime} 10^{\prime \prime}$ \\
\hline Weight & 320 & 300 & 240 & 250 \\
\hline \multicolumn{5}{|l|}{ Nurick status } \\
\hline Preoperatively & III & III & IV & II - III \\
\hline Postoperatively & 0 & 0 & I & 0 \\
\hline First operation & $\mathrm{ACF} \mathrm{C} 5-\mathrm{C} 7$ & $\mathrm{ACF} \mathrm{C} 5-\mathrm{C} 7$ & $\mathrm{ACF} \mathrm{C} 2-\mathrm{C} 4$ & $\mathrm{ACF} \mathrm{C} 5-\mathrm{C} 7$ \\
\hline Graft & Fibula allograft & Fibula allograft & Fibula allograft & Iliac autograft \\
\hline Reason for graft & Obesity & Obesity & Wound depth & Obesity \\
\hline Complications & $\begin{array}{l}\text { Graft/plate } \\
\text { extrusion }\end{array}$ & Pseudarthrosis & $\begin{array}{l}\text { Pseudarthrosis } \\
\text { (delayed) }\end{array}$ & Delayed strut fracture \\
\hline Time to complication & 2 weeks & 6 months & 1.5 years & 6 months \\
\hline Secondary surgery & $\begin{array}{l}\text { ACF C } 5-\mathrm{T} 1 \\
\text { PWF C4-T2 }\end{array}$ & PWF C4-T1 & PWF C2-C6 & PWF C4-T1 \\
\hline $\begin{array}{l}\text { Time to fusion } \\
\text { after } 2 \text { nd surgery }\end{array}$ & 4 months & 4 months & 5 months & 4 months \\
\hline
\end{tabular}

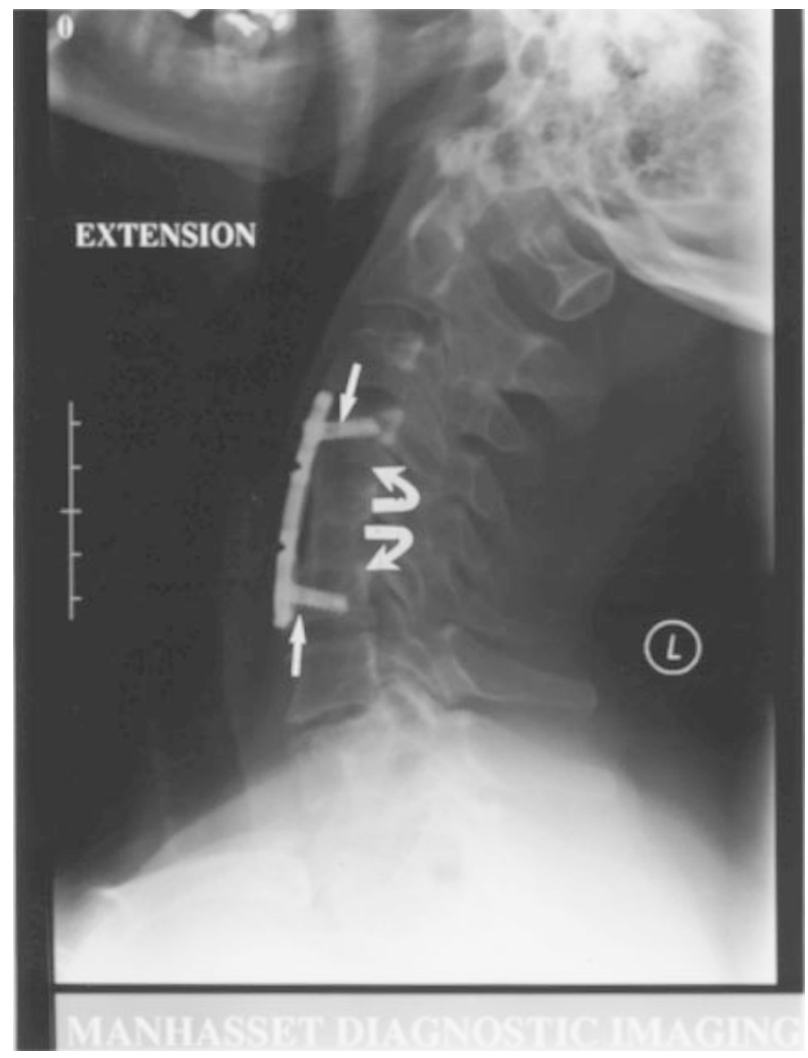

Figure 2 Case 1: Lateral extension X-ray obtained 6 months postoperatively demonstrating classical cephalad migration $(7 \mathrm{~mm})$ and caudad migration $(5 \mathrm{~mm})$ (white arrows) following a $\mathrm{C} 4-\mathrm{C} 6 \mathrm{ACF}$. The lack of lucency and presence of bony trabeculation at the graft/vertebral body interface was consistent with fusion (curved arrows)

The average postoperative cephalad plate migration was $5.3 \mathrm{~mm}$ (range $3-10 \mathrm{~mm}$ ) and the average caudad migration was $5.5 \mathrm{~mm}$ (range $2-10 \mathrm{~mm}$ ).

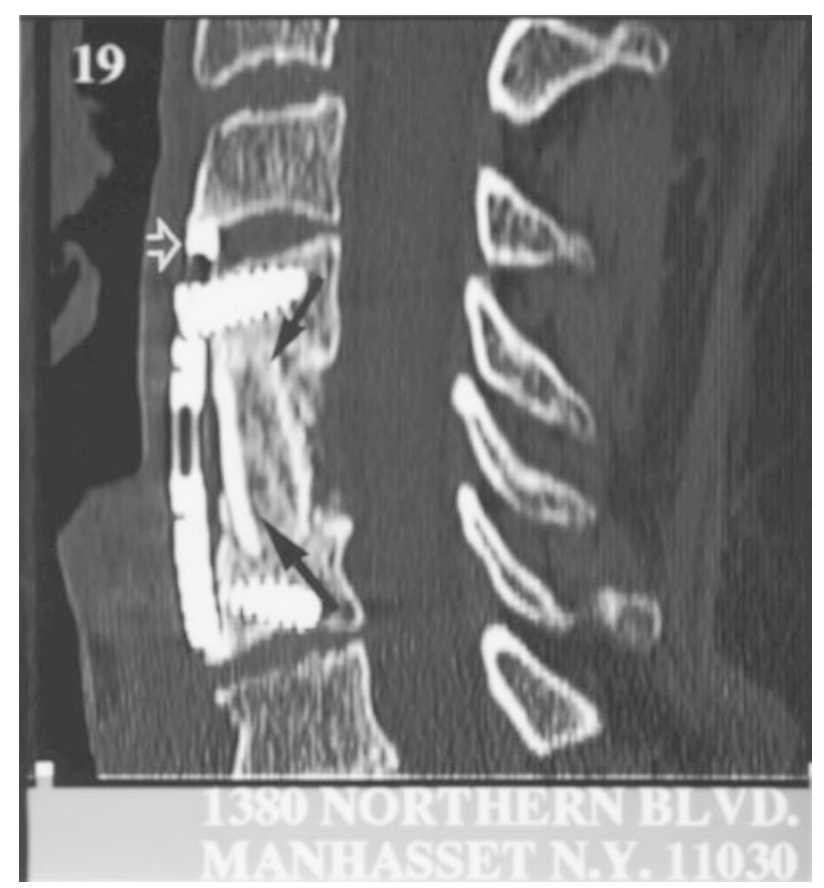

Figure 3 Case 2: Postoperative midline sagittal 2-D CT scan at 6 months confirmed adequate graft/fusion cephalad and caudad (long arrows), while confirming both cephalad and caudad migration of the plate. Note, superior extension of the plate impinging on the inferior aspect of $\mathrm{C} 3$ (short arrow)

Four $(9.5 \%)$ of 42 patients exhibited postoperative complications (Tables 1 and 2). A morbidly obese male 2 pack/day smoker, developed a graft/plate extrusion 2 weeks following a C5-C7 ACF utilizing a fibula strut allograft (Table 2, Case 1). Fusion was demonstrated 3 months following a secondary ACF $\mathrm{C} 5-\mathrm{T} 1$ with $\mathrm{C} 4-\mathrm{T} 1$ posterior wiring and fusion (PWF) and halo application. Two patients had single 


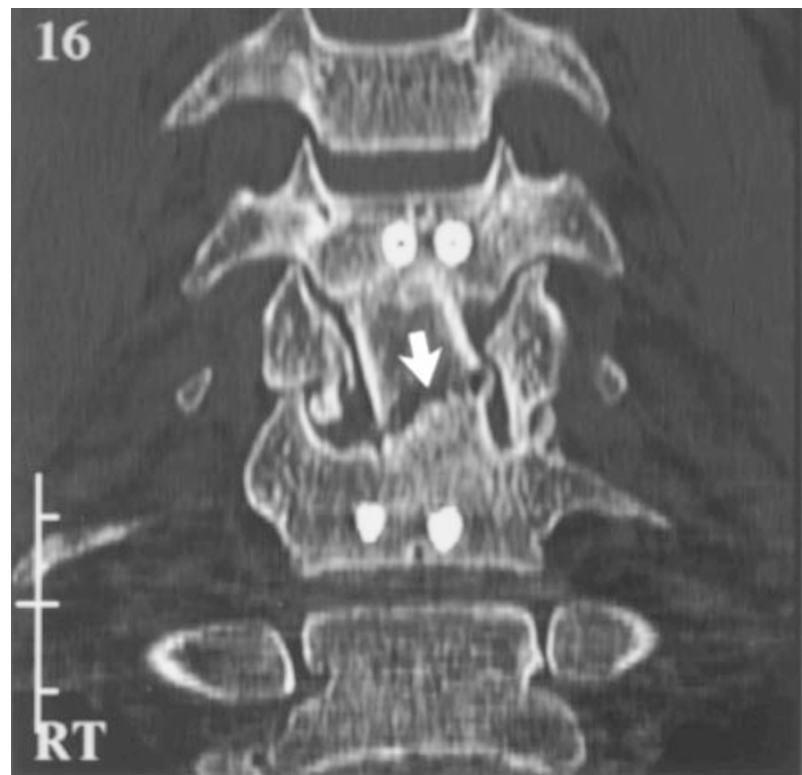

Figure 4 Case 3: Postoperative coronal CT at 6 months demonstrating a mid-lower spontaneous iliac crest strut fracture (arrow) following a $\mathrm{C} 5-\mathrm{C} 7 \mathrm{ACF}$

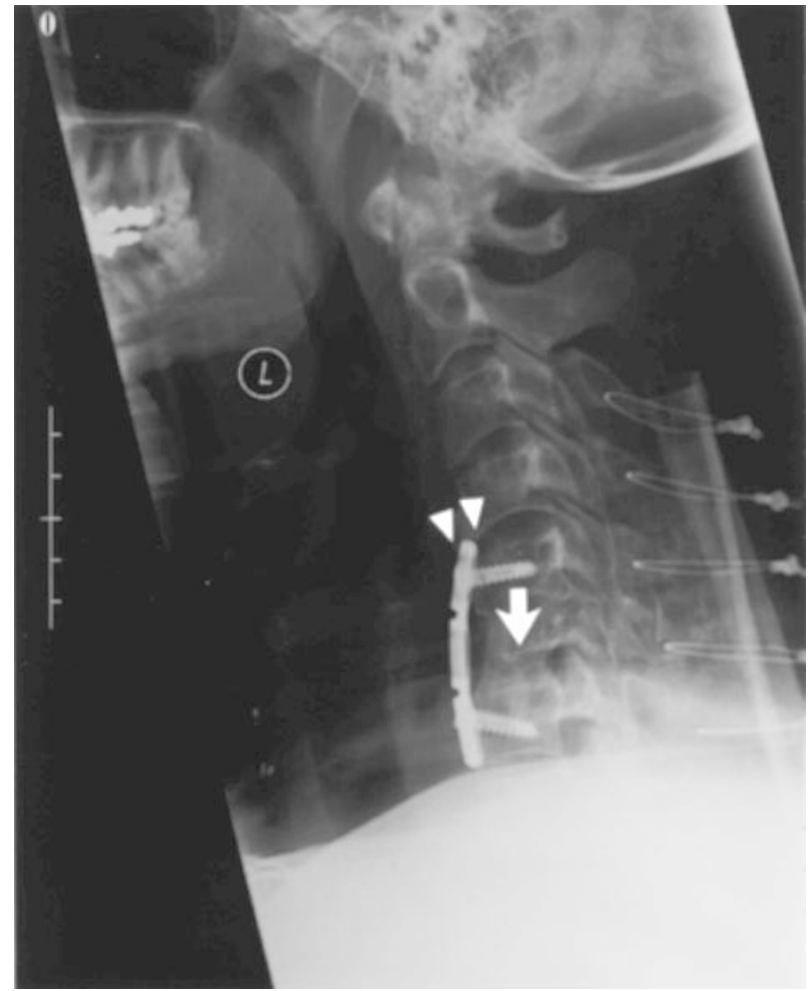

Figure 5 Case 3: Lateral plain radiograph obtained immediately following posterior wiring and fusion from $\mathrm{C} 3-\mathrm{T} 1$ addressing the spontaneous $\mathrm{C} 5-\mathrm{C} 7$ iliac crest strut fracture demonstrated in Figure 4. Note clear linear lucency in the mid-iliac crest strut graft anteriorly (arrow). Note the kyphotic deformity accompanying this construct, with superior impingement of the $\mathrm{ABC}$ plate on the anterior/inferior $\mathrm{C} 4$ vertebral body (arrows)

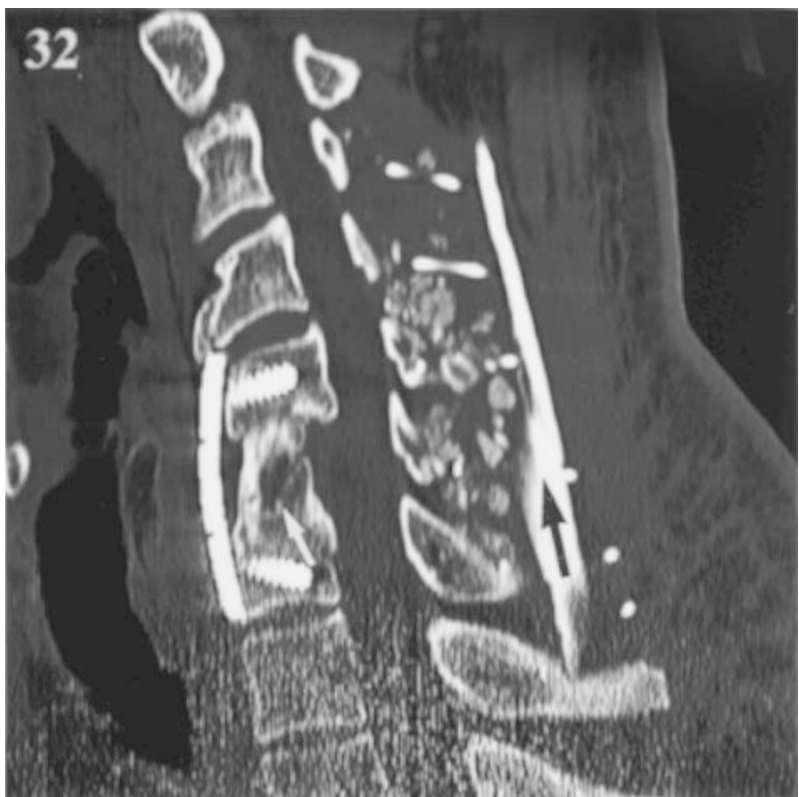

Figure 6 Case 3: Postoperative 2-D CT study at 6 months obtained from the same Case 3 in Figures 4 and 5 revealing progressive fusion of the iliac crest strut fracture (white arrow). The posterior wiring and fusion construct performed with a fibula strut allograft (black arrow) individually wired to the spinous processes shows multiple autogenous bony fragments contained within an inductive conductive matrix. Multiplanar reconstruction demonstrates laterally fused fragments

level ACF performed with fibula strut allografts, one with morbid obesity, and the other, for a technically difficult $\mathrm{C} 2-\mathrm{C} 4$ ACF (Table 2, Case 3). Here, pseudarthroses occurred respectively 6 months and 1.5 years postoperatively necessitating secondary $\mathrm{C} 4-$ T1 PWF with fusion 4 and 5 months later. The fourth patient had a C5-C7 ACF and demonstrated fusion on a 2D-CT scan 3 months postoperatively. $\mathrm{He}$ immediately returned to driving a truck against medical advice. Three months later, he presented with neck pain and a mid-iliac crest strut fracture (Table 2, Case 4) (Figure 4). He failed to fuse after wearing a Cervico-Thoracic Orthosis (CTO) for 6 months (at his request), required a secondary $\mathrm{C} 4-\mathrm{T} 1 \mathrm{PWF}$, and fused 4 months following the secondary fusion (Figures 5 and 6).

\section{Discussion}

Failures associated with non-plated anterior cervical procedures prompted the application of different types of anterior cervical plates. ${ }^{1-12}$ Emery et al found a $16 \%$ pseudarthrosis rate following $1-2$ level nonplated anterior diskectomy with fusion (ADF) or single level ACF. ${ }^{2}$ Epstein noted a $24 \%$ pseudarthrosis rate in non-plated 1-4 level ADF. ${ }^{14}$

The impact of fixed plates on single level ADF remains controversial. ${ }^{1,10,11,14-19}$ Caspar et al found a 
$9 \%$ incidence requiring secondary surgery in 210 patients with non-plated 1-2 level ADF, but only a $2 \%$ rate for those with 146 similarly plated procedures. ${ }^{16}$ Anterior cervical plates increased fusion rates for $1-2$ level ADF up to $97.9 \%{ }^{15}$ and $100 \%{ }^{1}$ in some series, while decreasing pseudarthrosis, graft, and plate extrusion rates. ${ }^{11,16,18}$ Biomechanical data confirmed that single level ADF plates provided load-sharing rather than load-shielding and facilitated fusion. ${ }^{20}$

Dynamic plates appear to provide an added benefit for multilevel constructs. ${ }^{1,13}$ Saunders documented three plate/graft failures in 31 four level $A C F{ }^{21}$ Using fixed plates for multilevel ACF alone, Vaccaro et al demonstrated a $9 \%$ failure rate for two level ACF, and $50 \%$ incidence for three level $\mathrm{ACF}^{22}$ Performing 2-4 level ACF with a posterior tension band (posterior wiring and fusion), Epstein also found that three of 22 non-plated, and five of 38 fixed plated cases failed. ${ }^{6-8}$ In 26 dynamic plated multilevel $\mathrm{ACF} /$ PWF, only one failure was observed, resulting in a partial pseudarthrosis necessitating a secondary PWF. ${ }^{8}$

The $9.5 \%$ dynamic $\mathrm{ABC}$ failure rate following single level ACF in 42 patients appears high, but below our initial experience with fixed plates. The biomechanical advantages of dynamic plates include reduced stress shielding and greater graft compression. However, two factors which contributed significantly to increased morbidity include performing only anterior constructs in the morbidly obese and utilizing less effective fibula strut allografts. Construct failures would be reduced in the morbidly obese patient if simultaneous posterior fusions were performed. Di Angelo et al, looking at the in vitro biomechanics of load transfer through multilevel strut-grafts using a comparable single level ACF model, determined that multilevel anterior cervical plates reversed graft loads and excessively loaded anterior grafts in extension, promoting graft pistoning. ${ }^{23}$ Simultaneous application of a posterior tension band in obese individuals would presumably limit this reversal and thus reduce construct failures. The fibula allograft remains suboptimal in single level ACF when performed without a simultaneous posterior tension band. Contributory factors against utilizing allograft fibula include the shallow graft/vertebral-end plate base and the tendency for hard cortical fibula grafts to piston through the inferior vertebra. Also a longer period is required for such grafts to incorporate. Alternatively, iliac crest autografts with the combination of cortical and cancellous bone, provide a wider graft/vertebral base reducing the tendency for inferior pistoning and a more rapid incorporation. In morbidly obese patients, if donor site morbidity is to be avoided, a fibula strut allograft in association with a single level ACF should be accompanied by a PWF. The described advantages of dynamic plating systems should further contribute to an overall reduction in morbidity. Dynamic plate failures and their relationship to patient-related comorbidities require further evaluation in a larger series of patients.

\section{References}

1 Connolly PJ, Esses SI, Kostuik JP. Anterior cervical fusion: outcome analysis of patients fused with and without anterior cervical plates. J Spinal Disord 1996; 9: $202-206$.

2 Emery SE, Bohlman HH, Bolesta MJ, Jones PK. Anterior cervical decompression and arthrodesis for the treatment of cervical spondylotic myelopathy. Two to seventeen year follow up. J Bone Joint Surg (AM) 1998; 80: $941-951$.

3 Epstein NE. Advanced cervical spondylosis with ossification into the posterior longitudinal ligament and resultant neurologic sequelae. J Spinal Disord 1996; 9: $477-484$.

4 Epstein NE. Vertebral body fractures following extensive anterior cervical surgical procedures for ossification of the posterior longitudinal ligament. Neuro-Orthopaedics 1997; 21: $1-11$.

5 Epstein NE. Evaluation and treatment of clinical instability associated with pseudarthrosis after anterior cervical surgery for ossification of the posterior longitudinal ligament. Surg Neurol 1998; 49: 246-252.

6 Epstein NE. Circumferential surgery for the management of ossification of the posterior longitudinal ligament. $J$ Spinal Disord 1998; 11: 200-207.

7 Epstein NE. The value of anterior cervical plating in preventing vertebral fracture and graft extrusion following multilevel anterior cervical corpectomy with posterior wiring/fusion: indications, results, and complications. J Spinal Disord 2000; 13: 9-15.

8 Epstein NE. The efficacy of anterior dynamic plates in complex cervical surgery. J Spinal Disord 2002, 15: 221 227.

9 Grubb MR et al. Biomechanical evaluation of anterior cervical spine stabilization. Spine 1998; 23: 886-892.

10 MacDonald RL et al. Multilevel anterior cervical corpectomy and fibular allograft fusion for cervical myelopathy. J Neurosurg 1997; 86: $990-997$.

11 McAfee PC et al. One-stage anterior cervical decompression and posterior stabilization. A study of one hundred patients with a minimum of two years follow-up. $J$ Bone Jt Surg Am 1995; 77: 1791-1800.

12 Richman JD et al. Biomechanical evaluation of cervical spine stabilization methods using a porcine model. Spine (US) 1995; 20: $2192-2197$

13 Wang JC et al. The effect of cervical plating on singlelevel anterior cervical discectomy and fusion. $J$ Spinal Disord (US) 1999: 12: 467-471.

14 Epstein NE. Anterior cervical diskectomy and fusion without plate instrumentation in 178 patients. $J$ Spinal Disord 2000; 13: $1-8$.

15 Bose B. Anterior cervical fusion using Caspar plating: analysis of results and review of the literature. Surg Neurol (US) 1998; 49: 25-31.

16 Caspar W, Geisler FH, Pitzen T, Johnson TA. Anterior cervical plate stabilization in one- and two-level degenerative disease: overtreatment or benefit? J Spinal Disord 1998; 11: $1-11$.

17 Geisler FH, Caspar W, Pitzen T, Johnson TA. Reoperation in patients after anterior cervical plate stabilization in degenerative disease. Spine 1998; 23: 911 - 920.

18 Kostuik JP, Connolly PJ, Esses SI, Suh P. Anterior cervical plate fixation with the titanium hollow screw plate system. Spine 1993; 18: $1273-1278$. 
19 Lowery GL, McDonough RF. The significance of hardware failure in anterior cervical plate fixation. Patients with 2-7 year follow up. Spine 1998; 23: $181-$ 186.

20 Rapoff AJ et al. Anterior cervical graft and plate load sharing. J Spinal Disord (US) 1999; 12: 45-49.

21 Saunders RL. Four-level cervical corpectomy. Spine (US) 1009; 23: $2455-2461$.
22 Vaccaro AR et al. Early failure of long segment anterior cervical plate fixation. J Spinal Disord (US) 1998; 1195: $410-415$.

23 Di Angelo DJ et al. Anterior cervical plating reverses load transfer through multilevel strut-grafts. Spine (US) 2000; 25: $783-795$. 